\title{
Selected Papers from NAFEW 2009
}

\author{
Terry L. Sharik ${ }^{1}$ and J. P. Hamish Kimmins ${ }^{2}$ \\ ${ }^{1}$ Department of Wildland Resources, College of Natural Resources, Utah State University, Logan, UT 84322, USA \\ ${ }^{2}$ Department of Forest Science, Faculty of Forestry, University of British Columbia, Vancouver, BC, Canada V6T $1 Z 4$
}

Correspondence should be addressed to Terry L.Sharik, terry.sharik@usu.edu

Received 18 February 2010; Accepted 18 February 2010

Copyright (c) 2010 T. L. Sharik and J. P. Hamish Kimmins. This is an open access article distributed under the Creative Commons Attribution License, which permits unrestricted use, distribution, and reproduction in any medium, provided the original work is properly cited.

Our understanding of the ecology and management of North American forests is rapidly evolving as a result of novel approaches to their study, many of which are the results of emerging technologies. The biennial North American Forest Ecology Workshop series attempts to capture these approaches and highlight the ways in which they expand our understanding of forest systems. The ten papers appearing in this issue were drawn from the 7th and most recent workshop, held in June 2009, in which there were over 150 presentations.

The first paper in this special issue attempts to provide an overview of emerging themes in the ecology and management of North American Forests based on all presentations and follow-up discussions at the workshop and concludes with future research needs. The second paper describes the carbon flux of down woody materials in forests of the Northcentral U.S. using recent data from the USDA Forest Service's Forest Inventory and Analysis (FIA) Program and exemplifies the utility of a network of permanent plots for monitoring change over large spatial scales and long time periods. The study described in the third paper is a nice sequel to the second in that it uses FIA data to demonstrate changes in the population levels of an understory tree in eastern North America threatened by an introduced pathogen, among other causes. The authors point out that such data can be used to validate the findings of multiple small-scale studies and to generate hypotheses for testing at smaller scales, thereby reinforcing a workshop-wide call for the study of forest ecosystems at multiple scales.

The fourth paper describes a rapid assessment method for extending the use of Reineke's stand density index (SDI), originally developed for even-aged, monotypic stands, to mixed species stands in the Northeastern U.S, utilizing point sampling in combination with wood specific gravity to harmonize the density of individual species. The fifth paper applies SDI in combination with tree diameter distributions to characterize complex forest stands in the Florida Keys, which in turn are used as reference sites or standards for restoring forest structure in Everglades tree islands. The sixth paper describes the application of a fairly recently devised environmental variable, Landform Index, in predicting the site index of mesophytic tree species in the Southern Appalachians, in turn reflecting the quality of these sites relative to the production of tree biomass.

The seventh through ninth papers address some dimension of fire as a disturbance agent in North American forests. The first of these and the seventh paper in the special issue is said to represent the first attempt to develop a comprehensive model for predicting fire-induced slash pine mortality in pine forests of the Florida Keys, which in turn may provide insights into the management of these sites through the use of prescribed fire. The situation is complicated by storm surges and associated increases in substrate salinity, which differ in their effect on the structure of slash pine-dominated forests compared to fire, and may be increasingly important with climate-change-mediated increases in the frequency and intensity of tropical storms and in sea level rise. The eighth paper examines the effects of soil temperature during fire on the survival of seeds of herbaceous perennials and woody shrubs in Florida sand pine ecosystems and suggests that small-scale variation in soil surface temperatures is important in the regeneration of these species. The ninth paper reports on the results of laboratory studies aimed at determining the physiological 
effects of short-duration smoke exposure on six species of hardwoods and conifers native to the Intermountain West, a phenomenon that has been little studied in the past. Inconclusive with respect to effects on growth or secondary defense compound production in these species, it points to the need for research on the effects of longer-term exposure to smoke.

The tenth and final study examines the potential effects of global increases in the intensity and complexity of radio frequency background on forest decline, using trembling aspen seedlings as a model. Preliminary in nature, the results point to the need for more robust studies of a potentially significant anthropogenically induced impact on forest ecosystems.

Terry L. Sharik J. P. Hamish Kimmins 

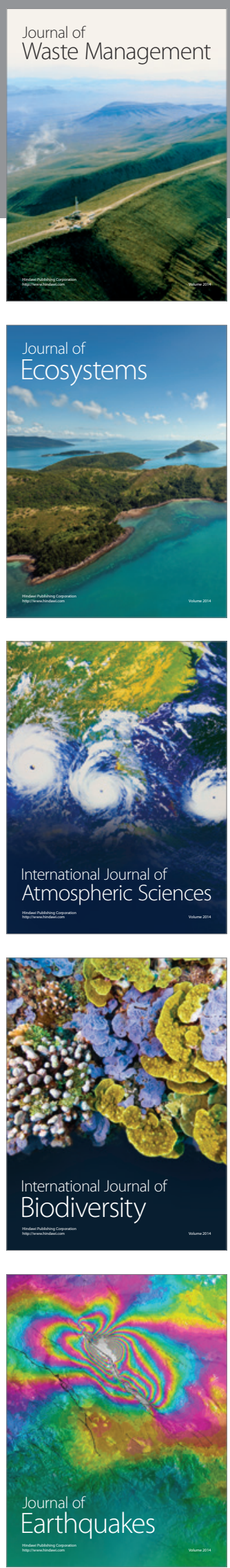
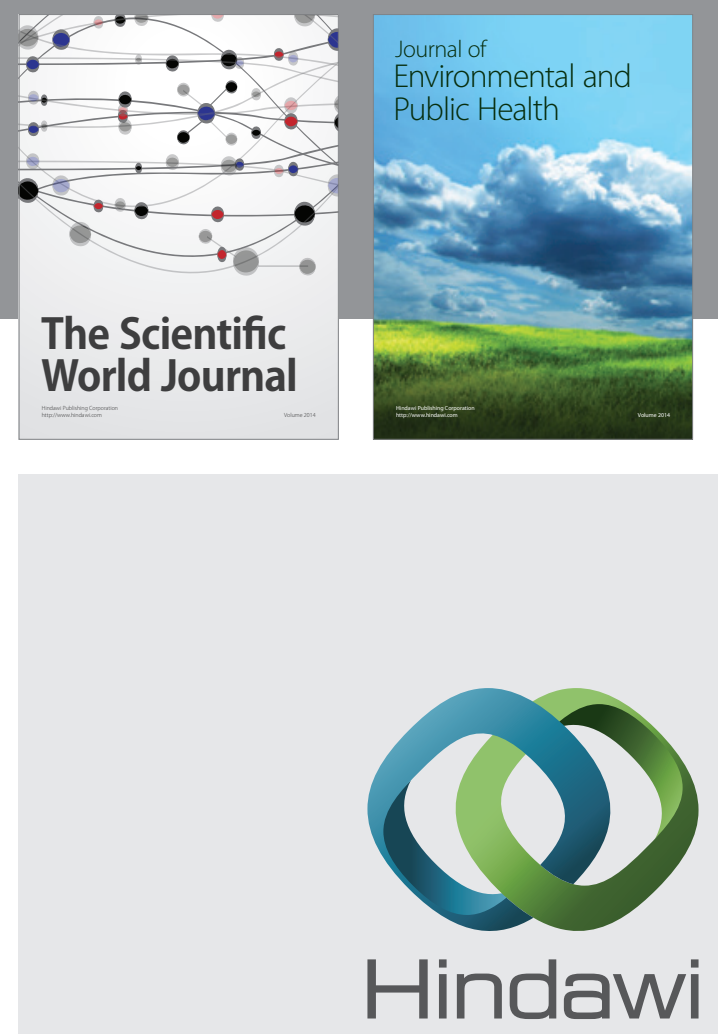

Submit your manuscripts at

http://www.hindawi.com
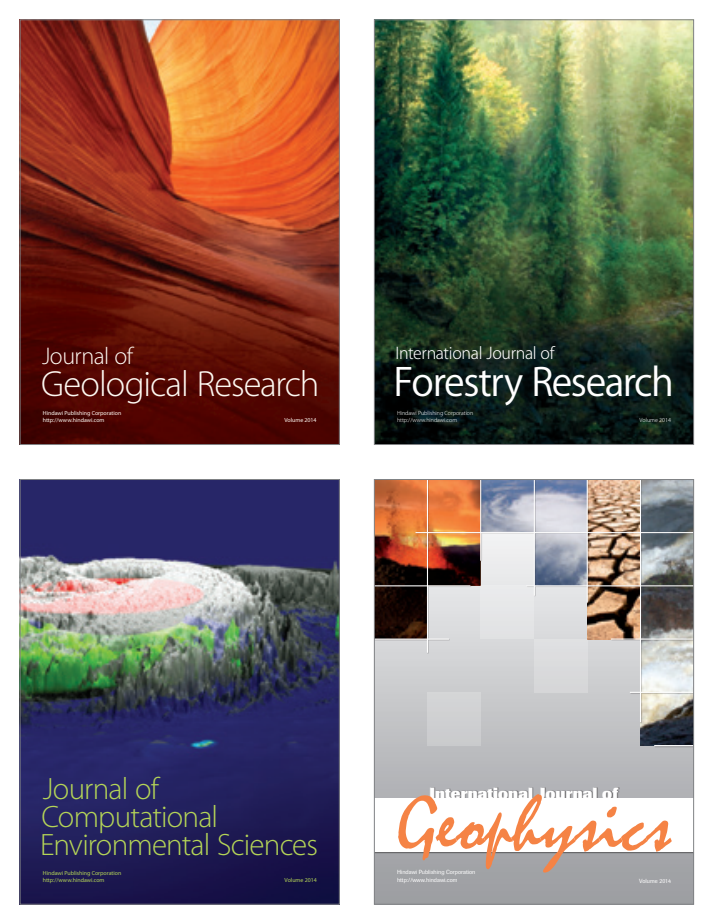
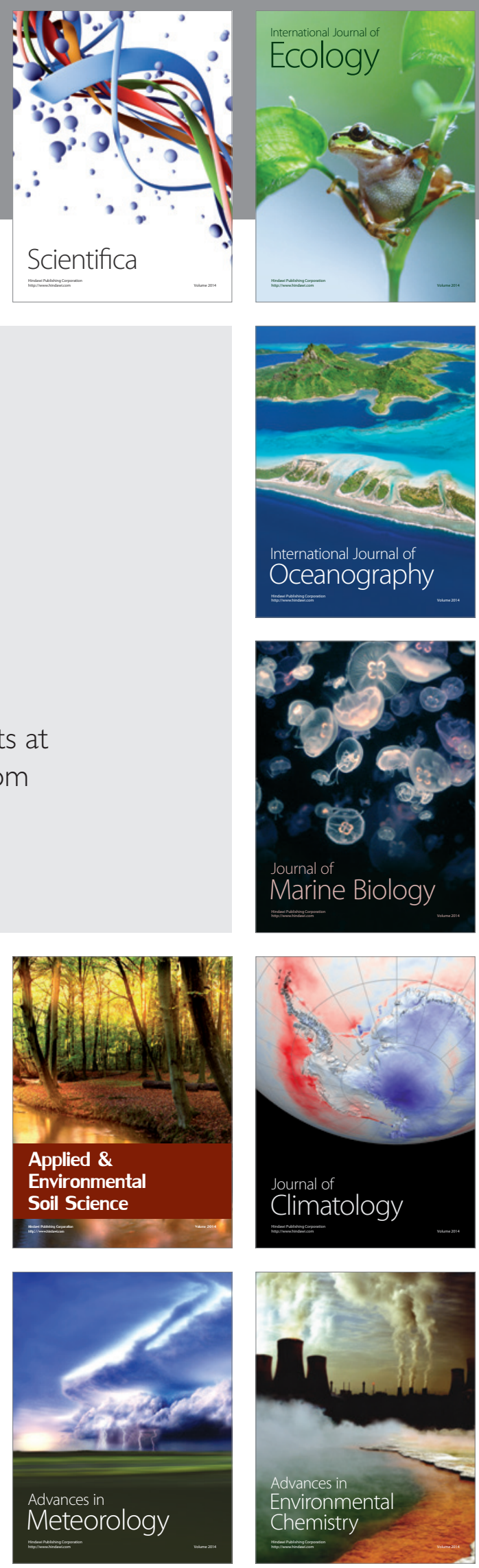